\title{
Watson, uso de Inteligência Artificial (AI) e processos educativos em museus
}

Watson, use of Artificial Intelligence (AI) and educational processes in museums

\author{
Watson, uso de Inteligencia Artificial (Al) y procesos educativos en museos
}

Milene Chiovatto ${ }^{1}$

\section{RESUMO}

O presente artigo reflete sobre o uso de tecnologia de inteligência artificial junto ao público como recurso de mediação em museus. A primeira experiência desse recurso, foi acompanhada por método de observação e avaliação espontânea dos usuários e a partir deste estudo de caso serão apresentados alguns resultados e reflexões desde o ponto de vista da educação museal. A Pinacoteca de São Paulo, Brasil, foi o primeiro museu do mundo a utilizar a tecnologia Watson, da IBM, para propiciar um recurso interativo com percursos modelados a partir das perguntas do público. A proposta partiu da IBM e envolveu as áreas de educação, curadoria, comunicação e marketing do museu. Selecionamos 7 obras emblemáticas de nosso acervo, em exposição de longa duração e recolhemos digitalmente potenciais perguntas que tais obras despertariam. Após isso, auxiliamos a construção de respostas potenciais. Em uso desde abril 2017, o recurso atraiu visitantes frequentes, mas também aqueles que nunca tinham visitado o museu. Será esse o futuro?

PALAVRAS-CHAVE: Educação museal. Inteligência artificial. Museu. Arte.

\section{ABSTRACT}

This article reflects on the use of artificial intelligence technology with the public as a mediation resource in museums. The first experience of this resource was accompanied by a method of observation and spontaneous evaluation of the users and from this case study will be presented showing some results and reflection, from the point of view of museum education. The Pinacoteca de São Paulo, Brazil was the first museum in the world to employ IBM's Watson technology as interactive resource with modeled questions from the public. The proposal was brought forward by IBM and involved the museum's education, curatorial, communication and marketing departments. We selected 7 emblematic artworks from our collection on display in long-term exhibitions, and digitally collated potential questions that these works might evoke. After that, we assisted in the construction of potential answers. In use since April this year, this resource has attracted frequent visitors, as well as people who had never visited the museum before. Is this the future?

KEYWORDS: Museum education. Artificial intelligence. Museum. Art.

\section{RESUMEN}

En el presente artículo se refleja acerca del uso de tecnología de inteligencia artificial junto al público como recurso de mediación en museos. La primera experiencia de este recurso, fue acompañada por método de observación y evaluación espontánea de los usuarios, de este estudio de caso se presentarán algunos resultados y reflexiones

Submetido em: 09/02/2019 Aceito em: 12/04/2019 Publicado em: 31/08/2019.

${ }^{1}$ Núcleo de ação Educativa da Pinacoteca de São Paulo.

\begin{tabular}{l|l|l|l|l|l|l} 
(C) Redoc & Rio de Janeiro & v. 3 & n.2 & p. 217 & Maio/Agosto 2019 & ISSN 2594-9004
\end{tabular}


desde el punto de vista de la educación museal. La Pinacoteca de São Paulo, Brasil, fue el primer museo del mundo en utilizar la tecnología Watson, de IBM, para propiciar visitas educativas (recurso interactivo) modeladas a partir de las preguntas del público. La propuesta partió de IBM e involucró las áreas de educación, curaduría, comunicación y marketing del museo. Seleccionamos 7 obras emblemáticas de nuestro acervo, en exposición de larga duración y recogemos digitalmente potenciales preguntas que tales obras despertar. Después de eso, ayudamos a construir respuestas potenciales. En uso desde abril de este año, el recurso atrajo a visitantes frecuentes, pero también a aquellos que nunca habían visitado el museo. ¿Será ese el futuro?

PALABRAS CLAVE: Educación museal. Inteligencia artificial. Museo. Art.

\section{INTRODUÇÃO}

A Pinacoteca de São Paulo, Brasil, é o mais antigo museu de arte deste estado, tendo sua coleção dedicada a arte brasileira desde o século XVII até os dias de hoje.

Localizado na megalópole paulistana, que abriga cerca de 12 milhões de pessoas, fica na área central da cidade, ao lado de um parque, numa região com boa infraestrutura urbana, porem que sofreu distintos momentos de degradação social.

Além de seu acervo representativo da identidade brasileira, o museu tem também uma longa tradição em processos educativos, sendo referência na área desde a década de 1980. A partir de 2002, sob a liderança de uma nova direção, inicia também um novo momento em sua trajetória educativa, formando o Núcleo de Ação Educativa.

As propostas deste Núcleo estão interessadas na ampla acessibilidade ao museu e no equilíbrio entre quantidades de visitantes e qualidade das experiências educativas que pode promover. Além disso, voltam-se aos diferentes perfis de públicos, desde os mais cotidianos, como escolas, professores e famílias; aos mais distanciados da frequência e gosto pela cultura, tais como as pessoas com deficiência, pessoas em situação de vulnerabilidade social, idosos e até os próprios funcionários do museu. 
Em 2016 a IBM (International Business Machines) empresa americana e a maior do mundo na área de tecnologia da informação $(\mathrm{TI})^{2}$ procurou a Pinacoteca de São Paulo, para propor a utilização do Watson.

Watson $^{3}$ é um recurso interativo que utiliza Inteligência Artificial (AI) a fim de simular diálogos com os visitantes.

O termo Inteligência artificial começou a ser utilizado em 1956 em Dartmouth, a partir da idéia de construir computadores com as mesmas características do cérebro humano. Entretanto, com a tecnologia disponível naquela época, só se conseguiu desenvolver tecnologias capazes de realizar uma única tarefa específica de forma otimizada em relação aos humanos. Por isso, naquele momento, nomearam o processo de Inteligência Artificial Limitada. Este processo ainda permanece em uso em algoritmos como os usados para separar imagens no Pinterest, por exemplo.

O próximo passo rumo ao Watson, foi o desenvolvimento do que é chamado Machine Learning (máquinas de aprendizagem), que além de coletar os dados de bigdata ${ }^{4}$ da web, são capazes de aprender a partir destes dados e fazer alguma predição ou determinação sobre algo do mundo. Assim, ao invés de apenas realizar algo específico, a máquina é treinada a partir de uma grande quantidade de dados e algoritmos que dão a ela a possibilidade de executar uma tarefa.

Finalmente chegou-se ao Deeping Learning, chamado em português de Computação Cognitiva, neste estágio, camadas discretas de dados tentam imitar a conectividade de nossa rede neural biológica. Estas camadas de conexão são capazes, não apenas de aprender a como realizar uma tarefa, mas de avaliar -baseando-se em grandes quantidades de dados - se uma informação (dado, imagem, etc.) tem probabilidade em ser verdadeira ou não. Embora a idéia de redes neurais estivesse presente desde o início de IA, apenas com os recursos tecnológicos atuais elas

\footnotetext{
2 Com quase 400.000 colaboradores em mais de 150 países, a IBM detém mais patentes do que qualquer outra empresa americana de tecnologia e tem 15 laboratórios de pesquisa no mundo inteiro.

${ }^{3} \mathrm{O}$ sistema recebeu o nome Watson, em homenagem ao primeiro CEO da IBM, o industrial Thomas J. Watson.
}

4 Big data é o termo que descreve o imenso volume de dados - estruturados e não estruturados - que impactam os negócios no dia a dia pode ser analisado para a obtenção de insights que levam a melhores decisões e direções estratégicas de negócio. O conceito ganhou força no início dos anos 2000, quando um analista famoso deste setor, Doug Laney, articulou a definição de big data como os três Vs: volume, velocidade e variedade. 
se tornaram factíveis. Apenas quando os cientistas conseguiram paralelizar os algoritmos ${ }^{5}$ para avançar para além da capacidade de realizar algo, reconhecer e analisar respostas corretas e erradas e "aprender". Assim, por exemplo, ao invés de basear suas buscas de respostas em palavras-chave da pergunta e em sua recorrência nas milhares de páginas da web, esta tecnologia está preparada para compreender a intenção da pergunta e entregar respostas mais coerentes. Outra diferença fundamental dos sistemas de IA antigos e o Deep Learning é o reconhecimento da fala natural humana e sua interpretação e portanto, possibilidade de mímese de interação.

Enquanto as "redes neurais" dos sistemas computacionais estão sendo ajustadas, elas estão constantemente produzindo respostas erradas. E por isso ainda é necessário muito trabalho manual humano: a tecnologia precisa de treino. Precisa de milhares de milhões de informações para poder calibrar suas respostas e, posteriormente, acertar praticamente todas as vezes. Atualmente este tipo e tecnologia está em uso em várias funções: desde o reconhecimento facial do facebook, até a leitura de tumores em exames de ressonância magnética, por exemplo. Por enquanto a associação entre a análise humana e a da máquina tem porcentagem de acerto maior que cada um destes recursos utilizado sozinho. Mas, o futuro parece bastante próximo.

Dizem os especialistas que é possível treinar as máquinas para responder qualquer pergunta. As possibilidades são infinitas, bastando ensiná-las.

Mas, o que este tipo de tecnologia pode realizar no campo dos museus?

Podem as tecnologias de Inteligência Artificial produzir criativamente?

Até agora estamos falando em recolhimento de dados, análise e respostas corretas a determinadas perguntas. Mas seria "criar” um atributo específico humano?

É necessário ser criativo para trabalhar num museu?

5 Computação paralela é uma forma de computação em que vários cálculos são realizados ao mesmo tempo, operando sob o princípio de que grandes problemas geralmente podem ser divididos em problemas menores, que então são resolvidos concorrentemente (em paralelo). 
Sobre este dilema, foi feito um teste utilizando Computação Cognitiva como redator de um curta metragem de ficção científica ${ }^{6}$.

O resultado foi ininteligível. Ao menos para nós... ao menos por enquanto...

Antes de definirmos se o desenvolvimento tecnológico chegará a criar, precisamos nos perguntar se todas as tividades desenvolvidas num museu exigem criação. Outra querstão é se - no caso de um museu de Arte - é possível afirmarmos uma única verdade absoluta como resposta a uma determinada pergunta, por exemplo. Poderia esta tecnologia realizar curadorias, recolhendo, analisando e reinterpretando os dados de obras do acervo?

Por se tratar de uma questão filosófica maior do que este texto permite, não enfrentaremos esta polêmica aqui, restringindo o artigo e suas relfexões a como foi desenvolvido o projeto de parceria entre o recurso Watson e a Pinacoteca, numa das primeiras ações que envolveram IA e museus; como foi seu uso e algumas conclusões a qual podemos chegar.

O projeto, chamado $A$ Voz da $A r t e^{7}$, envolveu as áreas de educação, curadoria, comunicação e marketing do museu, além de equipes externas de design; programação digital; comunicação visual; publicidade e consultores em História da Arte Brasileira.

A Pinacoteca foi o primeiro museu do mundo em utilizar esta tecnologia para fins de mediação e a proposta era criar visibilidade para os potenciais que este tipo de tecnologia responsiva pode alcançar, tendo o museu como plataforma.

\section{DESENVOLVIMENTO DO PROJETO}

\footnotetext{
${ }^{6}$ Sunspring é um curta metragem de ficção científica, resultado de uma parceria entre o cineasta Oscar Sharp e o pesquisador da New York University Ross Goodwin. O acadêmico alimentou uma tipo de IA que é comumente utilizado para reconhecimento de textos, chamado Rede neural recorrente de memória longa e de curto prazo (ou LSTM para encurtar) com roteiros de filmes de ficção científica como Highlander, Ender's Game, Interestelar, O Quinto Elemento e Os CaçaFantasmas e instruiu o computador a gerar um roteiro baseado nos argumentos selecionados pelo Festival de CurtasMetragens de Ficção Científica de Londres. O script foi filmado e protagonizado por Thomas Middleditch (Silicon Valley). 0 vídeo pode ser visto aqui https://voutu.be/LY7X2/hqimc e mais informações podem ser conseguidas aqui https://arstechnica.com/gaming/2016/06/an-ai-wrote-this-movie-and-its-strangely-moving/
}

${ }^{7}$ O vídeo de divulgação do projeto pode ser acessado aqui: https://www.youtube.com/watch?v=1rOAgvCnZpw

\begin{tabular}{l|l|l|l|l|l|l|} 
(C) Redoc & Rio de Janeiro & v. 3 & n.2 & p. 221 & Maio/Agosto 2019 & ISSN 2594-9004
\end{tabular}


A partir da proposta da IBM, as áreas de curadoria e educação selecionaram juntas 7 obras das exposições de longa duração com obras do acervo do museu que apresentam obras de artistas brasileiros desde o século XVIII até a contemporaneidade, buscando oferecer o máximo de abrangência nesta escolha e - geograficamente - perpassar todos os andares de exposição, impulsionando o deslocamento do visitante usuário do equipamento pelo espaço da instituição.

A intenção com estas escolhas foi também selecionar obras ricas em informação, ao mesmo tempo que mobilizadoras de perguntas.

As obras selecionadas foram:

José Ferraz de Almeida Junior (Itu, São Paulo, Brasil, 1850 - Piracicaba, São Paulo, Brasil, 1899)

Saudade, 1899

óleo sobre tela

197 x 101 x $0 \mathrm{~cm}$

Nelson Leirner (São Paulo, São Paulo, Brasil, 1932)

O Porco, 1967

engradado de madeira e porco empalhado

$83 \times 159 \times 62 \mathrm{~cm}$

Rubens Gerchman (Rio de Janeiro, RJ, 1942 - São Paulo, SP, 2008)

Lindonéia, A Gioconda do Subúrbio, 1966-1968

Serigrafia sobre papel

$50 \times 50,1 \mathrm{~cm}$ 
Lasar Segall (Vilna, Lituânia, 1889 - São Paulo, São Paulo, Brasil, 1957)

Bananal, 1927

óleo sobre tela

$87 \times 127 \mathrm{~cm}$

Antonio Parreiras (Niterói, Rio de Janeiro, Brasil, 1860 - Niterói, Rio de Janeiro, Brasil, 1937)

Ventania, 1888

óleo sobre tela

$150 \times 100 \mathrm{~cm}$

Tarsila do Amaral (Capivari, São Paulo, Brasil, 1886 - São Paulo, São Paulo, Brasil, 1973)

São Paulo, 1924

óleo sobre tela

$57 \times 90 \mathrm{~cm}$

Candido Portinari (Brodowski, São Paulo, Brasil, 1903 - Rio de Janeiro, Rio de Janeiro, Brasil, 1962)

O mestiço, 1934

óleo sobre tela

$81 \times 65 \mathrm{~cm}$ 
A segunda fase do projeto foi o lançamento de uma plataforma digital de 'recolhimento de perguntas'. Durante algumas semanas a IBM criou um hotsite com acesso apenas a usuários autorizados, no qual convidados dos profissionais da IBM e Ogilvy (agência de publicidade), além dos profissionais do museu e seus convidados, podiam deixar expressas suas dúvidas, em forma de perguntas, sobre as obras selecionadas. Desde as mais comuns e banais, como qual o nome do autor da obra até as mais insólitas e interpretativas (grande preocupação da área de educação já que sabemos a mobilização do imaginário de que a arte é capaz), como critérios de beleza, interpretações possíveis, histórias fantásticas etc.

Foram fornecidas diferentes bases de dados e pesquisa para coletar respostas potenciais as possíveis perguntas: livros, pesquisas acadêmicas, materiais educativos, catálogos etc.

Levantadas as questões, foi o momento de organizá-las por similaridade. Assim, uma única resposta deveria servir para responder a diferentes questões, por exemplo, o nome do artista serviria de resposta a diferentes questões como:

- Quem fez esta obra?

- Quem é o autor?

- De quem é a pintura?

- Qual o nome desse artista?

etc.

Depois destas aglutinações, foi o momento de aferirmos as respostas possíveis. Percebemos que a quantidade de trabalho gerada pelo projeto era superior ao que a instituição podia assumir internamente apenas com os profissionais do museu (já envolvidos em seus próprios projetos e atuações) e assim, foi recomendada a contratação de uma pesquisadora de História da Arte terceirizada para aferir as respostas.

A dificuldade desta etapa foi a de construir textos que respondiam as questões com dados corretos, mas, ao mesmo tempo com abrangência suficiente para poder relacionar-se com diferentes questões, além de verificar a propriedade das fontes eventualmente citadas.

\begin{tabular}{l|l|l|l|l|l|r|} 
(C) Redoc & Rio de Janeiro & v. 3 & n.2 & p. 224 & Maio/Agosto 2019 & ISSN 2594-9004
\end{tabular}


Feito este processo, foi tempo de desenhar a interface do recurso para com o visitante, sistemas de navegação bem como os circuitos espaciais e suas respectivas indicações para que os visitantes pudessem percorrer para encontrar todas as obras, passando por dois andares e sete diferentes salas expositivas.

A ativação do recurso digital do Watson se deu via beacons ${ }^{8}$ colados em lugares estratégicos do edifício que simulam acompanhar o visitante. Assim, se estiver numa sala lateral de uma das imagens selecionadas, o recurso chamará sua atenção para ela, com frases como - Você está próximo da obra Saudade, tem alguma pergunta para mim?, numa simulação geoespacial de estar a todo o tempo junto ao visitante operador do sistema.

Isso indica ao visitante como percorrer os espaços, se o interesse dele for acompanhar todas as obras presentes no Watson, por exemplo.

\section{PROCESSO DE UTILIZAÇÃO DO WATSON NO MUSEU}

Foi desenvolvida uma interface bastante amigável como forma de promover a interação entre o visitante e o Watson, utilizando-se de recursos já conhecidos pela maior parte da população como mensagens e gravação de voz. Uma experiência simples de utilização oferece condições para realizar diferentes perguntas frente às obras: seu contexto histórico, as datas de sua produção, seus significados históricos, iconográficos e até interpretações possíveis.

Estas perguntas podem ser feitas via digitação, numa interface como o whatsapp, ou por voz, utilizando o microfone do smartphones fornecidos pelo Projeto ao público. Os smartphones ficaram disponíveis a empréstimo ao público em geral do museu, mediante preenchimento de formulário de empréstimo com dados pessoais dos visitantes.

Pessoas contratadas para este fim, permaneceram na recepção do museu e forneceram, junto com os smartphones, um fone de ouvido aos visitantes interessados.

\footnotetext{
${ }^{8}$ Beacon é um dispositivo tecnológico de geolocalização para ambientes fechados, ou seja, é um sistema de proximidade. É como se fosse um rastreador GPS, porém para curtas distâncias, internas. Em conjunto com a interface criada como meio para utilização do recurso Watson, os beacons criam a ilusão de operar conjuntamente ao visitante, acompanhando-o em seus deslocamentos, embora estivessem dispostos pelo espaço do museu.
} 
Se alguma questão do público não estivesse contemplada no script prévio do repertório de respostas possíveis do recurso, o mecanismo jamais tentava minimizar seu desconhecimento e respondia sinceramente: 'não sei'. Por mês foram realizadas produzidas cerca de 15.000 novas questões, ou seja, questões sem resposta previa pré-programada; sendo que cerca de $7 \%$ delas foi respondida com 'não sei'.

Sobre uma das obras mais icônicas da produção brasileira da década de 1960, durante a ditadura militar no país, Lindonéia, gioconda do subúrbio; do artista Ruben Gerchman; ao tentarmos desafiar o recurso lançando uma pergunta plenamente interpretativa como 'Ela é bonita?', encontramos uma resposta surpreendente!

O recurso primeiro pareceu analisar graficamente a obra, dizendo ser difícil percebermos a face da personagem, uma vez que os traços foram simplificados e grandes áreas de sombra foram transformadas em superfície para melhor adaptar-se a técnica da serigrafia. Mas o comentário mais interessante da resposta veio a seguir, com o Watson tecendo considerações sobre o conceito de beleza como algo mutável no tempo, e que também tem relação com a subjetividade dos indivíduos, e que ao final a beleza dependia do ponto de vista de cada um. Toda essa resposta foi dada de uma maneira bastante coloquial, finalizando a conversa de maneira a instigar o visitante com um provocativo: não é?

\section{PRIMEIROS PARECERES SOBRE O USO DESTA TECNOLOGIA EM MUSEUS}

A partir do ponto de vista da educação museal é fundamental garantir que o acesso ao museu seja o mais amplo possível, e que os visitantes possam ter à sua disposição a maior variedade e gama de recursos ou possibilidades que promovam o contato com as obras de arte, ou objetos museológicos; pois assim, mais pessoas terão a responsabilidade compartilhada de zelar pelo patrimônio cultural coletivo e poderão fruí-lo com qualidade.

Entretanto, ainda baseada nas premissas da educação museal, é perceptível que o recurso Watson ainda não promove um verdadeiro diálogo com o público sobre o patrimônio, e nesse

\begin{tabular}{l|l|l|l|l|l|l|} 
(C) Redoc & Rio de Janeiro & v. 3 & n.2 & p. 226 & Maio/Agosto 2019 & ISSN 2594-9004
\end{tabular}


caso a arte. O diálogo, assim como a geolocalização e as interfaces do sistema, ainda é apenas uma simulação, posto que os mecanismos de IA não são capazes de continuar uma conversação ou desenvolver um raciocínio lógico de comunicação continuada, a partir das perguntas/falas coletadas do público. Trata-se apenas de sequências de perguntas e respostas. Ainda.

O desenvolvimento de um diálogo real, entretanto, é apenas questão de tempo e do quanto irá tomar o desenvolvimento de tecnologias responsivas cada vez mais ágeis e capazes de simular o funcionamento das capacidades cognitivas do cérebro humano.

Hoje em dia esta é uma tecnologia cara e rara. Então é necessário que nos perguntemos qual é o real interesse em introduzir-se este nível de tecnologia no museu, hoje? Ou seja, numa instituição que - por definição - não tem fins lucrativos?

É preciso compreender que neste momento, quando a tecnologia ainda é nova e cara, utilizá-la num museu possibilita visibilidade da tecnologia numa esfera privilegiada pela sociedade e garante a ela valores agregados (luxo, riqueza, conhecimento, identidade etc) pela associação com o Museu e a Arte.

A proposta não visa, por enquanto, substituir quaisquer profissionais de museus ou assumir para si suas especialidades. Os usos pretendidos - ao menos neste momento - não são produzir essa cara tecnologia para operar em museus, e sim oferecer o recurso para empresas, que podem pagar por este tipo de tecnologia.

A observação da utilização do Watson durante meses no museu, garantiu a percepção de que a publicidade gerada por esta tecnologia estimula o interesse em públicos que normalmente não visitam o museu, nem se interessariam por questões da arte ou patrimônio; mas interessam-se pela novidade desta mídia e se fascinam com o potencial da tecnologia. E, naturalmente, é positivo atrair um público tão diferente ao museu! Entretanto, o fascínio pelo recurso digital que hoje enfrentamos deixa claro que a experiência com a tecnologia muitas vezes suplanta a experiência com a arte. Seria possível no futuro ultrapassarmos o nosso interesse por novos meios digitais e resgatar o prazer de estar frente à arte? Também não é possível determinar nesse momento se os públicos mobilizados pela tecnologia e inovação voltarão ao museu, ou mesmo se eles passarão a interessar-se pela cultura ou pela arte futuramente. 
Foi possível notar, ainda, que crianças abaixo dos 7 anos, tanto pela dificuldade de expressão, seja verbal seja escrita, e por seu grande interesse em movimentar-se fisicamente e utilizar a imaginação, parecem desinteressar rapidamente por esse recurso, e aprovar recursos educativos mais tradicionais como jogos e atividades. Os visitantes idosos também não demostraram muito interesse em utilizar o recurso, talvez pela natural dificuldade de contato com a tecnologia, embora o Watson tenha demonstrado grande compatibilidade com a maior parte dos visitantes, principalmente para os mais jovens, sendo que os que o utilizaram apreciaram bastante o recurso, com aprovação superior a $85 \%$.

A maior demanda feita nas avaliações por parte dos usuários é que todas as obras em exposição estivessem conectadas ao Watson. Esse é um dado que carece de maior reflexão e, do ponto de vista institucional, talvez não seja o ideal, posto que o excesso de informação por vezes abafa o potencial surpreendente e instigante da arte. A maior quantidade de reclamações foi em relação ao funcionamento do recurso, ou por falta de respostas, ou por dificuldades técnicas. Algumas reclamações sobre a pronúncia mecânica dos nomes de artistas e obras, e muitos elogios à oportunidade de experiência com a tecnologia.

O projeto permaneceu em uso por cerca de um ano e três meses. Durante os primeiros quatro meses em que esteve à disposição (abril a julho de 2017), o museu recebeu mais de 80.000 visitantes, dos quais mais de 25.000 utilizaram o Watson. Neste mesmo período foram geradas 212.000 perguntas. $\mathrm{O}$ público avaliou que apenas $15 \%$ das respostas fornecidas pelo recurso não foram satisfatórias, numa grande demonstração de satisfação frente ao aparato.

Há diferentes maneiras de fruir o patrimônio, a cultura, a arte e de visitar museus. Há ainda, diferentes maneiras de "dialogar" com o público: textos de parede, educadores, folhetos, jogos, audio-guias e agora, o Watson. Para cada expectativa diferente dos visitantes, uma maneira diferente de experimentar o museu é possível.

Seriam as formas de mediar o encontro com a arte, tão múltiplas como a própria arte?

Será a Inteligência Artificial o futuro do museu? E da educação?

Serão as tecnologias de computação cognitiva o futuro da humanidade?

Poderiam os recursos como Watson substituir o contato com o outro? 
Por enquanto, ainda cabe a nós, humanos, emprestar à máquina nosso discernimento, aferindo a validade e adequação de suas respostas. É possível que no futuro a tecnologia prescinda de nós até para isso. Entretanto, há que perguntar-se se no mundo de hoje, mais do que nunca, cabe a nós, homens, decidirmos se precisamos (ou queremos) substituir outro humano por uma máquina.

\section{REFERÊNCIAS}

AIDAR, Gabriela; CHIOVATTO, Milene. Ação educativa em museus. In: PARK, Margareth Brandini; FERNANDES, Renata Sieiro; CARNICEL, Amarildo (org.). Palavras-chave em educação não-formal. Holambra/Campinas: Ed. Setembro/Unicamp-CMU, 2007. pp.57-58.

CABRAL, Magaly. $\mathbf{O}$ educador de museu frente aos desafios econômicos e sociais da atualidade. In: Musas - Revista Brasileira de Museus e Museologia. Brasília: IPHAN, n1, 2004. pp.27-33.

CHIOVATTO, Milene. Educação líquida: reflexões sobre o processo educativo nos museus a partir das experiências do Núcleo de Ação Educativa da Pinacoteca do Estado. In: CHIOVATTO, Milene (coord.). Anais do Encontro Internacional Diálogos em Educação, Museu e Arte [CD-ROM]. São Paulo: Pinacoteca do Estado de São Paulo, 2010.

CHIOVATTO, Milene; AIDAR, Gabriela; SOARES, Luís Roberto; Amaro, Danielle. Repensando a acessibilidade em museus: a experiência do Núcleo de Ação Educativa da Pinacoteca do Estado de São Paulo. In: SANTOS, Anderson (org.). Diálogos entre Arte e Público. Acessibilidade Cultural: o que é acessível e para quem? Caderno de textos III. Recife: Fundação de Cultura Cidade do Recife, vol.3, 2010. pp.18-21.

COELHO, H. Inteligência Artificial em 25 lições. Fundação Calouste Gulbenkian, 1995.

COSTA, E. e SIMÕES, A. Inteligência Artificial, Fundamentos e Aplicações. FCA, 2004.

DEWEY, John. A arte como experiência. In: Experiência e Natureza; Lógica-A Teoria da Investigação; A Arte como Experiência; Vida e Educação; Teoria da Vida Moral. São Paulo: Abril Cultural, 1980. pp.89-105.

FREIRE, Paulo. Educação como Prática da Liberdade, Rio de Janeiro 1967, tradução francesa.

HALL, Stuart. A identidade cultural na pós-modernidade. Rio de Janeiro: DP\&A, 2000.

\begin{tabular}{l|l|l|l|l|l|r|} 
(C) Redoc & Rio de Janeiro & v. 3 & n.2 & p. 229 & Maio/Agosto 2019 & ISSN 2594-9004
\end{tabular}


HEIN, George E. Learning in the museum. London: Routledge, 1998. Pgs. 16 e 21.

HOOPER-GREENHILL, Eilean (ed.). The educational role of the museum. Londres e Nova York:

Routledge, 1994.

\section{SITES CONSULTADOS:}

https://arstechnica.com/gaming/2016/06/an-ai-wrote-this-movie-and-its-strangely-moving/ (dez. 2017)

https://www.ibm.com/watson/br-pt/?S PKG=\&cm mmc=Search Google- -Consolidated+Advertising Pillars- -BR BR- inteligencia+artificial Broad \&cm mmca1 $=000027 \mathrm{HR} \& \mathrm{~cm}$ mmca2 $=10008442 \& \mathrm{mkwid}=\mathrm{k}$ CjwKCAiA767jBRBqEiwAGdAOr 78I8rNYDIMUJZcRceSbHUpQtc2SXoD-GQdR8LLX-

JqaUrBzEGkg8RoCat8QAvD BwE k $|748| 828 \&$ cvosrc=ppc.google.inteligencia\%20artificial\&cvo campaign=Consolidated\% 20Advertising Pillars-

BR BR\&cvo crid=304646397528\&Matchtype=b\&gclid=CiwKCAiA767jBRBqEiwAGdAOr78I8rNYDIMUJZcRceSbHUpQtc2SXo D-GQdR8LLx-JqaUrBzEGkg8RoCat8QAvD BwE (dez. 2017)

https://usemobile.com.br/conheca-beacon/ (março 2018)

https://www.sas.com/pt br/insights/big-data/what-is-big-data.html (março 2018) 